\title{
PROPERTIES OF EQUILIBRIUM STRATEGIES \\ IN MULTIPLE-UNIT, UNIFORM-PRICE AUCTIONS
}

\author{
Michal Břeský
}
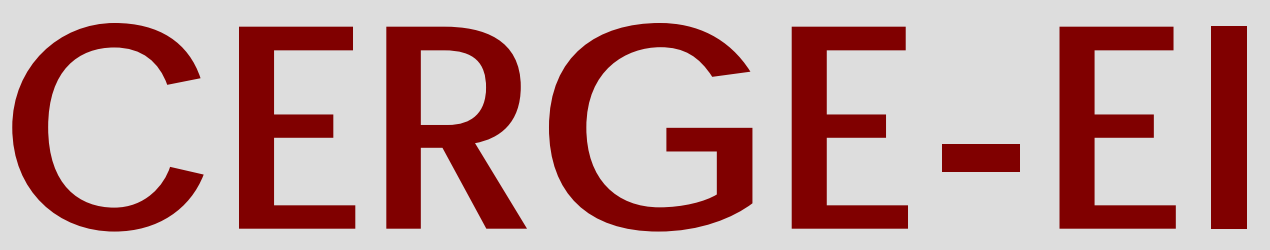

Charles University Centerfor Ec onomic Research and Graduate Education Academy of Sciences of the Czech Republic Ec onomic s Institute 


\section{Working Paper Series 354 (ISSN 1211-3298)}

\section{Properties of Equilibrium Strategies in Multiple-Unit, Uniform-Price Auctions}

Michal Břeský

CERGE-EI

Prague, May 2008 
ISBN 978-80-7343-154-9 (Univerzita Karlova. Centrum pro ekonomický výzkum a doktorské studium)

ISBN 978-80-7344-143-2 (Národohospodářský ústav AV ČR, v.v.i.) 


\title{
Properties of Equilibrium Strategies \\ in Multiple-Unit, Uniform-Price Auctions
}

\author{
Michal Břeský*
}

CERGE-EI ${ }^{\dagger}$

\begin{abstract}
The paper analyzes the essential properties of bidder equilibrium strategies in the multi-unit uniform-price auction. In the auction the seller offers several identical units for sale, specifies a minimum accepted bid (reservation price) and sets maximum number of bids that any bidder can submit. Under these restrictions bidders use strictly increasing strategies in a symmetric equilibrium more often, and in many cases the reservation price increases the bidder's strategy which is typical in single-unit auctions. Such an auction procedure implies a unique equilibrium strategy in some cases. Thus the number of bid restriction and reservation price present in real-life multi-unit auctions restore some properties of equilibrium strategies typical for single-unit auctions.
\end{abstract}

\begin{abstract}
Abstrakt
Studie analyzuje základní vlastnosti rovnovážných strategií pro účastníky víceobjektové aukce $\mathrm{s}$ jednotnou cenou. V této aukci aukcionář nabízí na prodej několik jednotek stejného zboží, stanoví nejnižší nabídku, kterou přijímá (maximální výnos), od účastníků aukce a stanoví nejvyšší počet jednotek, na kolik může každý účastník podat nabídky. Takováto aukční procedura zajístí, že rovnovážná strategie je v některých př́ípadech jednoznačná. Zavedením těchto dvou omezení na rovnovážné strategie, které se často objevují v běžných pravidlech více-jednotkových aukcí s jednotnou cenou, mohou způsobit, že vlastnosti těchto rovnovážných strategií účastníků těchto aukcí se více přibližují vlastnostem rovnovážných strategií typickým pro aukce jedné jednotky zboží.
\end{abstract}

Keywords: multi-unit auction, uniqueness of equilibrium in discontinuous games, uniform-price auction with reservation price.

JEL Classification: D44.

\footnotetext{
*I would like to thank Philip Reny, Avner Shaked, Viatcheslav Vinogradov, Michal Kejak and Jan Hanousek for their helpful comments. I would appreciate any comments that can be sent to michal.bresky@cerge-ei.cz.

'CERGE-EI is a joint workplace of the Center for Economic Research and Graduate Education, Charles University in Prague, and the Economics Institute of Academy of Sciences of the Czech Republic
} 


\section{Introduction}

Recently auctions have attracted much more attention of practitioners and researchers than before. The theoretical results on multi-unit auctions are less straightforward and less powerful than in the single-unit case. Several studies have been devoted to uniform-price auctions showing some basic properties of equilibrium strategies, and addressing the question of efficiency of the final allocation and revenue raised by the seller. In Ausubel and Cramton (2002) it is shown that no uniform-price auction is efficient. The asymptotic results with large number of bidders were discussed in Swinkels (2001) and EngelbrechtWiggans and Kahn (2005). In an multi-unit auction an important policy tool is a reservation price. In Ausubel and Cramton (2004) a multi-unit Vickrey auction with perfect resale market is analyzed and argued that if the seller uses a reservation price an auction is efficient and revenue maximizing for any number of bidders. The auction results with small finite number of bidders are analyzed in Engelbrecht-Wiggans and Kahn (1998), Engelbrecht-Wiggans (1999). These studies show that in the multi-unit, uniform-price auction equilibria in which the auction price is zero exists.

This paper is focused on an uniform-price auction in which the seller sets a positive reservation price and restricts each of the bidders to buy less than a specific fraction of all units for sale. Then no bids at the reservation price are submitted. Moreover, a reservation price increases the bid each bidder submits in symmetric equilibrium given his valuation. In addition, the underrevelation illustrated in Ausubel and Cramton (2002), and Draaisma and Noussair (1997)

diminishes. Next, the so called "pooling" and "multiplicities of equilibria" mentioned in Engelbrecht-Wiggans and Kahn (1998) are often not present. In general, when the seller uses these policy tools in real-life he improves bidder's equilibrium behavior in the sense that more revenue is collected in expectation and auction inefficiency occurs less often. 
Intuitively submitted bids in an auction effect probability of winning units and auction price paid for units. Consider the case in which the bidder submits two bids in the uniform price auction. I will call the first unit bid an introductory bid and the second unit bid a successive bid. The strategic considerations on the introductory bid are similar to the single-unit, second-price auction. The introductory bid effects only the probability of winning and does not influence the price the bidder pays for the introductory unit. Therefore the bidder has an undominated strategy in the uniform-price auction to bid the true value on their introductory unit. The strategic consideration on a successive bid takes into account the case of being the first rejected bid. In other words this bid determines the price of one additional preceeding unit of this bidder. The successive bid increases both the probability of winning the unit and the price paid for the introductory unit in this case when the bid is the first-rejected one. This is similar to the single-unit, pay-your-bid auction. In this single-unit auction (see McAfee and McMillan (1987), Lizzeri and Persico (2000)) it is a standard result for symmetric equilibrium that the higher the private value or reservation price, the higher bid each bidder submits.

It seems that the uniform-price auction outcome is more sensitive to proper reservation price setting and the number of bids each bidder can submit than the pay-your-bid auction, which requires more information gathering and strategic considerations from the seller to design the auction properly. It eliminates some of the unfavorable equilibria from the point of view of auction efficiency and the seller's revenue. The conlusion drawn from this paper may be an argument as to why the seller should specify a reservation price and a limit on the number of units each bidder is allowed to bid as is observed in real-life, uniform-price auctions.

The structure of the paper is as follows. In the first section I specify a model of the uniform-price auction and discuss some essential properties of the 
equilibria. Since the bidders use strictly increasing strategies in equilibrium, no bidder bids at the reservation price with positive probability. Then I focus on symmetric equilibria in which each bidder submits at most two bids. Then the reservation price increases the bidders' strategies if one imposes simple restrictions on the distributions of values.

\section{The Uniform-price Auction Game}

I describe a model of multi-unit auctions with risk-neutral bidders having continuous distributions of private values. Let us consider a seller who plans to sell $k(k \geq 1)$ identical units to $n(n \geq 1)$ bidders each of whom submits $l$ bids. I assume that each bidder receives $l$ private values $v_{i}=\left[v_{i, 1}, \cdots, v_{i, l}\right]$ where $v_{i, j}$ is the value of the $j$ th unit that agent $i$ wins $(1 \leq j \leq l \leq k$, $1 \leq i \leq n)$. The marginal value from winning an additional unit weakly decreases for each bidder; i.e. $v_{i, j} \geq v_{i, j^{\prime}}$ if $j<j^{\prime}$. Symbol $\times$ means the Cartesian product. Let $H_{i}\left(v_{i}\right)$ that has support on an interval $\mathcal{V}_{i}=\times_{j=1}^{l}\left[0, \bar{v}_{j}\right]$ denote the probability distribution function of the private values $v_{i, j}$ where $\bar{v}_{j}$ 's $\left(\bar{v}_{1} \geq \cdots \geq \bar{v}_{l}\right)$ are the upper bounds of the support. The index $-i$ represents the set of indices $\{1, \cdots, i-1, i+1, \cdots, n\}$. To guarantee the existence of equilibrium, I assume that the values of $v_{i}$ of one bidder are independent of opponent values realization $v_{-i}$. Moreover for any $i=1, \cdots, n$, the marginal density function of the introductory unit $h_{i, 1}\left(v_{i, 1}\right)$ exists.

I impose the following technical condition on the distribution of values.

Condition C1. For $j=1, \cdots, l-1$ and for every $v>0$, there is a number $\varepsilon>0$ such that for any valuation $v_{j} P\left(v_{j+1}<v \mid v_{j}\right)>\varepsilon$.

In other words, condition $\mathrm{C} 1$ means that no matter whatever $v_{j}$ is, there is some chance that $v_{j+1}$ is close to 0 . This condition is valid if any open subset of $\mathcal{V}_{i}$ has a positive measure.

The Game. Before the auction the seller announces a number of units for sale and the reservation price $R \in[0, \infty)$. Each bidder submits $l$ sealed 
finite bids $b_{i, 1}, \cdots, b_{i, l} \in[0, \infty)$ that are denoted as $b_{i}$. If more than $k$ bids are submitted above the reservation price, then the seller chooses $k$ highest bids that win a unit in the auction. A tie occurs when $k$ th and $k+1$ st highest bids are equal and the seller breaks such a tie randomly. Note the possibility that other bids may be also tied with $k$ th and $k+1$ st highest bids. The auction price that each bidder pays for winning each unit is equal to $k+1$ st highest bid. If less than $k+1$ bids are submitted above or equal to the reservation price, then each of them wins a unit and pays the price $R$.

Bidder $i$ 's ex post payoff depends on the number of units he wins, $J_{i}$, the realization of his winning values, $v_{i}, \cdots, v_{J_{i}}$, his bids, $b_{i}$, opponent bids, $c$, and the reservation price, $R$.

$$
\hat{\pi}_{i}\left(v_{i}, b_{i}, c, R\right)=\sum_{j=1}^{J_{i}}\left(v_{i, j}-p\left(b_{i}, c, R\right)\right),
$$

where $p\left(b_{i}, c, R\right)$ is the auction price for winning each unit. Since the seller orders bids after submission, I can assume that the vector of opponent bids $c$ is ordered; i.e. $c_{j}$ is the $j$ th highest opponent bid. Similarly I assume without loss of generality that each bidder submits an ordered $l$-tuple of bids $b_{i, 1} \geq \cdots \geq b_{i, l}$. The set of all these $l$-tuples I denote as $\mathcal{B}_{i}$.

I will assume that bidders are symmetric and omit index $i$ if no new confusion arises when referencing to a general agent $i$. I denote $v_{-}$realization of all opponent values and their strategies as $b_{-}(\cdot)$.

A pure strategy is a list of submitted bids based on the observed information that bidder $i$ knows before the auction, including his private values, reservation price, the distribution of all bidder values, the number of units for sale, and the number of opponents. For the sake of simplicity I will write the pure strategy as a function of private values only. Then the pure strategy is a mapping $b(\cdot): \mathcal{V} \rightarrow \mathcal{B}\left(b(v)=\left[b_{1}\left(v_{1}, \cdots, v_{l}\right), \cdots, b_{k}\left(v_{1}, \cdots, v_{l}\right)\right]\right)$ such that each component $b_{j}(v)$ is a weakly increasing function in every argument $v_{j^{\prime}}$ 
(for $\left.1 \leq j^{\prime} \leq k\right)$, and $b_{j}(v) \geq b_{j+1}(v)$ for $1 \leq j \leq k-1$. The set of all these strategies I denote as $B$.

When opponents use strategies $b_{-}(\cdot)$, then the ex ante pointwise payoff to bidder $i$, whose values are $v$ and who bids $b$, is

$$
\pi\left(v, b \mid b_{-}(\cdot)\right)=E(\pi(v, b, c, R)) .
$$

The expectations are taken over by the opponent values $v_{-}$. The probability measure of $\pi(v, b, R)$ is induced by the opponent strategies $b_{-}(\cdot)$, and the random tie-breaking rule if a tie occurs with positive probability.

When the bidder $i$ uses pure strategy $b(\cdot)$, then his ex ante pure strategy payoff is

$$
\pi(b(\cdot))=E(\pi(v, b(v)))
$$

where the expectations are taken over $v$. The word payoff I use to mean the ex ante payoff if no new confusion arises.

Example 1. Let me derive the payoff $\pi\left(v_{1}, v_{2}, b_{1}, b_{2}\right)$ of the bidder who bids $b_{1}$, and $b_{2}$ for values $v_{1}$ and $v_{2}$ given the opponent strategies $b_{-}(\cdot)$. For $q=1,2$ $j=0,1 I$ denote $P_{k+1-q}(b)$ the probability that at most $k-2-q$ opponent bids are above $b$ given the opponent strategies.

If a bidder submits $b_{1} \geq R$ and such that no tie occurs, then the bidder wins an introductory unit if his bid $b_{1}$ is above the $k$ th highest opponent bid denoted as $c_{k}$. His payoff increases by $v_{1} \cdot P_{k}\left(b_{1} \mid b_{1} \geq R\right)$. In the case that $b_{2}<R$ the expected auction price the bidder pays in the auction is $\max \left(c_{k}, R\right)$. Therefore his payoff is $\pi_{1}=\int_{-\infty}^{b_{1}}\left(v_{1}-\max \left(c_{k}, R\right)\right) \cdot d P_{k}\left(c_{k} \mid b_{1} \geq R\right)=\left(v_{1}-b_{1}\right) \cdot P_{k}\left(b_{1}\right)+\int_{R}^{b_{1}} P_{k}\left(c_{k}\right) d c_{k}$. In the case that the bidder submits $b_{2} \geq R$ and such that no tie occurs, then the bidder wins a successive unit if his bid $b_{2}$ is above $k-1$ st opponent bid. 
His payoff increases by $v_{2} \cdot P_{k-1}\left(b_{2}\right)$. At the same time the expected auction price the bidder pays in the auction changes by

$$
\begin{aligned}
p_{2}= & -\left(\int_{-\infty}^{b_{2}} c_{k} \cdot d P_{k}\left(c_{k}\right)\right)+b_{2} \cdot\left(P_{k}\left(b_{2}\right)-P_{k-1}\left(b_{2}\right)\right) \\
& +2 \cdot\left(\int_{-\infty}^{b_{2}} \max \left(c_{k-1}, R\right) \cdot d P_{k-1}\left(c_{k-1}\right)\right) .
\end{aligned}
$$

The formula (2.4) is intuitive. If the bidder has been bidding $b_{2}<R$, then the auction price paid for the introductory unit would have been $\max \left(c_{k}, R\right)$. Now when bidding $b_{2} \geq R$, then the auction price is the same if $b_{2}$ is neither winning nor the first-rejected bid. On the other hand, if $b_{2}$ is winning or the first rejected bid $\left(b_{2}>c_{k-1}\right)$, the bidder will not pay $\max \left(c_{k}, R\right)$ but pays $b_{2}$ if $b_{2}$ is the first rejected bid or $2 \cdot \max \left(c_{k-1}, R\right)$ if $b_{2}$ is the winning bid $\left(b_{2}>c_{k-1}\right)$. The term $P_{k}\left(b_{2}\right)-P_{k-1}\left(b_{2}\right)$ is the probability that $b_{2}$ is the first rejected bid. Therefore the payoff increase from the successive bid is

$$
\pi_{2}=v_{2} \cdot P_{k-1}\left(b_{2}\right)+p_{2}=\left(v_{2}-b_{2}\right) \cdot P_{k-1}\left(b_{2}\right)+2 \cdot \int_{R}^{b_{2}} P_{k-1}\left(c_{k-1}\right)
$$

If the bidder submits such a bid that a tie occurs, the seller uses a random rule that breaks qth tied unit into the favor of bidder with probability $\alpha_{q}$ where $0<\alpha_{q}<1$. Therefore bidders payoff is $\left(v_{q}-b_{q}\right) \cdot \alpha_{q} \cdot P\left(b_{q}=c_{k+1-q}\right)$.

All cases analyzed above can be summarized in the following payoff formula

$$
\begin{aligned}
& \left(\left(v_{1}-b_{1}\right) \cdot\left(P_{k}\left(b_{1}\right)+\alpha_{1} \cdot P\left(b_{1}=c_{k}\right)\right)+\int_{\max \left(b_{2}, R\right)}^{b_{1}} P_{k}\left(c_{k}\right) d c_{k}\right) \cdot I\left(b_{1} \geq R\right) \\
+ & \left(\left(v_{2}-b_{2}\right) \cdot\left(P_{k-1}\left(b_{2}\right)+\alpha_{2} \cdot P\left(b_{2}=c_{k-1}\right)\right)+2 \cdot \int_{R}^{b_{2}} P_{k-1}\left(c_{k-1}\right)\right) \cdot I\left(b_{2} \geq R\right)
\end{aligned}
$$

In Bresky (1999) it is shown that if each bidder submits $k$ bids, then equilibrium exists. It implies the following lemma, which is proved in the Appendix that equilibrium also exists when bidders are restricted to submit less than $k$ bids and reveal its value in his introductory bid. 
Lemma 1. Consider the uniform-price auction game defined in Section 2. Then there exists an equilibrium in pure strategies such that $b_{1}(v, R)=v_{1}$.

Although I focus on pure weakly increasing strategies, it seems that they can be generalized to measurable strategies as well as a mixed strategy when the bidder mixes over a superset of weakly increasing strategies $B .^{1}$ The intuitive reason is that if the bidder is mixing or bidding nonmonotinically in equilibrium over some range of bids, then bids submitted into this range has the same probability of winning and the same effect on the auction price. Moreover any mixed best response strategy $m$ can be rearranged to strategy $b(\cdot)$ that places probability 1 on one pure weakly increasing strategy and gives the bidder the same payoff. For more details see McAdams (2006) or Bresky (1999).

Let me illustrate the game on a simple example.

Example 2. Suppose two units are auctioned, each of two bidders can submit two bids $(k=l=2=n)$. The density function of the introductory and successive value is $h\left(v_{1}, v_{2}\right)=\frac{2}{\bar{v}^{2}}$ if $\bar{v} \geq v_{1} \geq v_{2} \geq 0$ and otherwise $h\left(v_{1}, v_{2}\right)=0$ where $\bar{v}=\bar{v}_{1}=\bar{v}_{2}$ is the upper bound of the value support. Then it can be verified that the following is a symmetric Nash equilibrium strategy

$$
b_{1}\left(v_{1}, v_{2}, R\right)=v_{1} \text { and } b_{2}\left(v_{1}, v_{2}, R\right)=\left\{\begin{array}{c}
R \text { if } v_{2}>R \\
0 \text { if } v_{2} \leq R
\end{array} .\right.
$$

The same strategies form an equilibrium for any other distribution of values if $h_{1}\left(v_{1}\right)$ is weakly increasing.

\section{No Bidding at Positive Reservation Price with the Restricted Number of Submitted Bids}

When there is zero reservation price in Example 2, Engelbrecht-Wiggans and Kahn (1998) (cf. also Ausubel (2002)) discuss that it is fairly common to

\footnotetext{
${ }^{1}$ One can consider a set of measurable strategies with bounded variation for that the mixed strategy space exists.
} 
bid 0 in the uniform-price auction. These type of equilibria is fairly unfavorable for the seller in terms of revenue. In addition, efficiency loss in the final allocation of units often occurs. I will demonstrate that if the seller sets a small positive reservation price, then in equilibrium no bidder bids at a positive reservation price on the $j$ th unit for $j \leq \frac{k+1}{2}$ (up to the measure 0 set of values). In other words, if the seller restricts the bidders to buy at most $\frac{k+1}{2}$ units and sets a positive reservation price, then every bidder bids above $R$ for values above $R$ in symmetric equilibrium.

In section 1 I defined a tie from the seller's point of view. From the bidder's point of view, if a tie occurs with a probability of 0 in equilibrium, then it does not influence the bidder's payoff. When discussing ties in this context I always consider only the ties that occur with positive probability for given opponent strategies.

Example 3. Suppose that each of the two bidders can submit two bids $(l=2)$ as in Example 2 and also the distribution of bidder valuations is the same. But three units are auctioned $(k=3)$. Then any symmetric Nash equilibrium strategy satisfies

$$
\begin{aligned}
b_{2}\left(v_{1}, v_{2}, R\right) & =\frac{\left(v_{2}-R\right)^{2}}{(\bar{v}-R)}+R \text { for } v_{2}>R \text { and } \\
b_{1}\left(v_{1}, v_{2}, R\right) & =v_{1} \text { for } v_{1}>R
\end{aligned}
$$

up to a measure zero subset of values. It is a unique symmetric equilibrium strategy in the sense that bids below the reservation price on values below the reservation price do not influence the auction outcome.

After just adding one unit for sale there is a dramatic difference in equilibrium strategy. The additional unit for sale introduces a tie if the bidders would bid at $R$ with positive probability. Since each bidder prefers to win the tied unit, he has an incentive to compete by submitting higher bids that is 
greater than the incentive not to increase the bid due to the decrease in the auction price for the introductory unit.

The same mechanics are present in a single-unit, pay-your-bid auction up to the fact that a bid on a unit influences the price of that unit. That is why no bidder bids reservation price $R$ which has a value above $R$ given that $R$ is positive and the bidders are restricted to buy less than one half of the total number of goods for sale.

At first let me demonstrate that the strategy with a tie for a given opponent strategy is not the best response if the bidder bids below his value. Assume that the reservation price is 0 and consider a tie in strategies at $b_{i, j}$ that occurs with positive probability (see Figure 1 ). In the tie the opponent $k+1-j$ th highest bid is equal to $b_{i, j}$. If the bidder with value $v_{i, j}>b_{i, j}$ bids $b_{i, j}+\varepsilon$ instead of $b_{i, j}$, he wins the tied unit surely and slightly increases the price if his bid is the first rejected one. For small $\varepsilon$ his ex post and therefore ex ante payoff increases (by a jump). To use the weakly increasing strategy the bidder increases his strategy for slightly higher values but for sufficiently small $\varepsilon$ the set of these values is arbitrarily small. It has a negligible effect on the ex post and therefore ex ante auction price paid for any of his unit. Therefore the bidder's best response cannot be with a tie. The formal proof is presented in the Appendix. 
The inverse distribution $c_{k+1-j}$. Strategy of the bidder on the $j$ th unit.

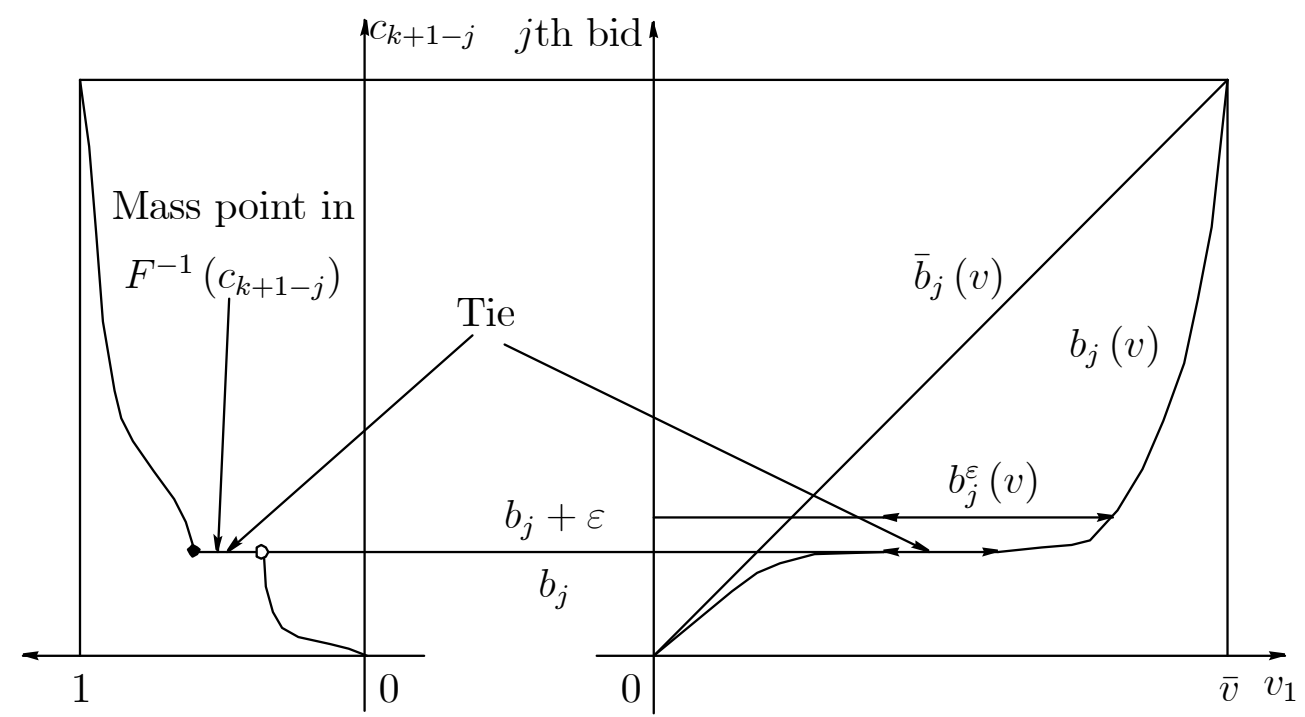

Figure 1: Increase in strategy by $\varepsilon$.

Lemma 2. Consider any given opponent strategies $b_{-}(\cdot) \in B_{-}$in the uniformprice auction game defined in Section 2. If the bidder uses such $b(\cdot)$ that a bid on jth bid is tied with positive probability with an opponent's bid and for any mass point $v \in \mathcal{V}$ the bidder does not bid his value $\left(b_{j}(v) \neq v_{j}\right)$, then a better response strategy $b^{\varepsilon}(\cdot) \in B$ exists for the bidder. 
Corollary 1. Assume that condition $C 1$ is valid, each bidder is restricted to submit at most $l$ bids where $l$ satisfies $n \cdot l>k>2 \cdot(l-1) \geq 2$, and none of the bidders have a mass point in probability distribution of a value at reservation price $R$ that is positive Then in no symmetric equilibrium bidders bid $R$ with positive probability. $^{2}$

It shows that the number of bids each bidder can submit influences bid submission at the positive reservation price. The importance of the condition $l \leq \frac{k+1}{2}$ is illustrated in Example 2 equation (2.6). The importance of the assumption $R>0$ can be seen from Example 4 in Section 4 . The seller can easily eliminate equilibria by bidding at the reservation price.

The restriction $l \leq \frac{k+1}{2}$ on the number of submitted bids is known from real-life, multi-unit, uniform-price auctions (e.g. Treasury bills). The seller typically restricts the bidders to buy at most one half or one third of the total amount for sale. In addition, the restriction $n \cdot l>k$ (or $\sum_{i} l_{i}>k$ in asymmetric case) is similar to the requirement that each bidder must submit several bids.

It seems that the seller who restricts the bidders to order a maximum share of the total amount for sale eliminates bidding at the reservation price in a uniform-price auction. Note also that in Example 3 the seller gains more revenue from each unit and sells more units than in Example 2.

\section{The Reservation Price Increases Equilibrium Strategy}

In this section I focus on symmetric bidders and symmetric equilibrium strategies when each bidder can submit two bids $(l=2)$. At first I briefly discuss why the symmetric equilibrium strategy on the introductory unit is

\footnotetext{
${ }^{2}$ If one considers asymmetric bidders and equilibrium strategies, then for any reservation price $R \in\left(0, \bar{v}_{l}\right)$ there is no equilibrium in which two bidders bid $R$ with positive probability. The restriction $n \cdot l>k$ can be relaxed to $\sum l_{i}>k$ where $l_{i}$ is the maximum number of bids each bidder $i$ can submit and $k>2 \cdot(l-1)$ to $k>l_{i}+l_{i^{\prime}}-2$ for any $i, i^{\prime}$.
} 
unique. Finally I show that the reservation price increases the continuous strategy.

In Lemma 1 is shown the existence of an equilibrium in which bidders submit their introductory value as an introductory bid. The reasons why this is a unique symmetric equilibrium strategy in most cases are similar to the Vickrey auction or the second-price auction. The introductory bid influences only the probability of winning and not the auction price the bidder pays for a unit. Consider such a realization of values of all bidders that $k-1$ bids are high and win, introductory values of the two bidders in the middle of the support compete for the $k$ th unit, and remaining bids are low and loose. If the first of the two bidders submits $b_{1}>v_{1}$ and the second's value $v_{1}^{\prime}$ is between $b_{1}, v_{1}$, then the second bidder cannot bid above $b_{1}$ otherwise he wins a unit for the price higher than his valuation. But if the second bidder bids his valuation $v_{1}^{\prime}$, he anticipates that the first bidder anticipates this and will not bid above $v_{1}^{\prime}$ having valuation $v_{1}$. Therefore the second bidder wins a unit for the price below his value and is better off when revealing his value. Since this is true for all $v_{1}^{\prime}$ between $b_{1}, v_{1}$ the first bidder cannot bid $b_{1}$ above his value $v_{1}$. Similar reasoning can be used to exclude the case that $b_{1}<v_{1}$.

This idea is summarized in the following two lemmas formally proved in the Appendix.

Lemma 3. If the number of bidders is greater than the number of units for sale and $H_{1}\left(v_{1}\right)$ is strictly increasing for $v_{1} \in\left[R, \bar{v}_{1}\right]$, then in any symmetric equilibrium $b_{1}\left(v_{1}, v_{2}, R\right)=v_{1}$ for all values with $v_{1} \geq R$ up to a measure zero subset.

Lemma 4. Consider a uniform-price auction in which condition $C 1$ is satisfied and assume that $n \leq k \leq 2 \cdot n-1$, in addition, $b_{2}(\cdot)$ is continuous if $k=$ $2 \cdot n-2,2 \cdot n-1$. Let me denote the highest successive bid in a symmetric 
equilibrium as $\bar{b}_{2}=b_{2}\left(\bar{v}_{2}\right)$. Then the introductory equilibrium strategy is $b_{1}\left(v_{1}, v_{2}, R\right)=v_{1}$ for all $v_{1} \in\left[R, \bar{b}_{2}\right]$ up to a measure zero subset.

The second lemma shows that the uniqueness of the introductory strategy depends on the successive strategy. And given the successive strategy the bidder may not reveal his value in a bid only if he submits such an introductory bid that has the same probability of winning as if bidding an introductory value (see e.g. Vickrey (1961)). It is a unique introductory strategy in the sense that such a change has no effect on the auction outcome. It is illustrated in the following example.

Example 4. Suppose there are $n \geq 2$ bidders with any distribution of values, $k=n$ units for sale and reservation price $R=0$. Then it can be verified that the following is a symmetric Nash equilibrium strategy:

$$
b_{1}\left(v_{1}, v_{2}\right)=\bar{v} \text { and } b_{2}\left(v_{1}, v_{2}\right)=0
$$

The bidder on the first unit bids above his value because he is sure he wins and the auction price will be 0 anyway. In the case of $n=k=2$ the equilibrium strategy differs from the strategy in the case of $R=0$ in Example 2. But the auction outcome is the same.

Moreover if $k=n-1, \ldots, 2 \cdot n-1$ one can easily check that $b_{2}\left(\bar{v}_{2}\right)=\bar{v}_{2}$. The reason is that if $b_{2}\left(\bar{v}_{2}\right)<\bar{v}_{2}$, then a bidder with value $\bar{v}_{2}-\delta$ prefers to bid above $b_{2}\left(\bar{v}_{2}\right)$ because he surely wins a successive unit. It may also increase the price he pays for the introductory unit (at most by $\left.b_{2}\left(\bar{v}_{2}\right)-b_{2}\left(\bar{v}_{2}-\delta\right)\right)$ but for sufficiently small positive $\delta$ the change is negligible with respect to a gain from winning the successive unit $\left(\bar{v}_{2}-\delta-b_{2}\left(\bar{v}_{2}\right)\right)$.

An implication of Lemma 3 and 4 is that without loss of generality one can restrict attention to the introductory strategy of the form 


$$
b_{1}\left(v_{1}, v_{2}, R\right)=\left\{\begin{array}{c}
v_{1} \text { for } v_{1} \in\left[0, \bar{b}_{2}\right) \\
\bar{v}_{1} \text { for } v_{1} \in\left[\bar{b}_{2}, \bar{v}_{1}\right]
\end{array} \text { where } \bar{b}_{2}=\left\{\begin{array}{c}
\bar{v}_{1} \text { if } 1 \leq k<n \\
b_{2}\left(\bar{v}_{2}, R\right) \text { if } k=n \\
\bar{v}_{2} \text { if } n<k<2 \cdot n
\end{array}\right.\right.
$$

From now on, I often omit the dependence of strategy $b_{2}(\cdot)$ and payoff $\pi(\cdot)$ on $R$ and $v_{1}$.

A bidder who submits a successive bid by positive sufficiently small $\varepsilon$ below his successive value is better off than if he bids his successive value. It decreases the price he pays for the introductory unit when his bid determines the auction price. The bidder also loses the successive unit more often but only when the price is close to his successive value that would yield him almost zero ex post payoff (see Lemma 6 in the Appendix). It implies that an introductory bid does not restrict the set of choices the bidder considers for a successive bid.

- McAfee and McMillan (1987) show a standard result of the single-unit pay-your-bid auction that in symmetric equilibrium a bidder's payoff can be expressed as a function of the bidder's value and bid. The parallel arguments for this are valid for the uniform-price auction model of this paper. If all bidders are symmetric and use the symmetric strategies and bid introductory value in the introductory bid, then $P_{k}(\cdot)$ can be expressed as a function of $b_{2}$ and $v_{2}$ only. Now consider the case that all bidders are symmetric and use symmetric strategies. Let $u_{2}\left(b_{2}\right)$ and $u_{1}\left(b_{2}\right)$ be the opponent inverse bid functions defined as $\sup \left\{u \mid b_{-2}(u)<b_{2}\right\}$ and as $\sup \left\{u \mid b_{-1}(u)<b_{2}\right\}$. Then

$$
P_{k}\left(b_{2}\right)=\sum_{\substack{2 i_{2}+i_{1} \leq k-1, 0 \leq i_{2}, i_{1} \leq n-1}} \frac{(n-1) !}{i_{2} ! i_{1} !\left(n-1-i_{2}-i_{1}\right) !} A^{i_{2}}\left(b_{2}\right) B^{i_{1}}\left(b_{2}\right) H_{1}^{n-1-i_{1}-i_{2}}\left(u_{1}\left(b_{2}\right)\right)
$$

where $A\left(b_{2}\right)=1-H_{2}\left(u_{2}\left(b_{2}\right)\right)$ is the probability that the two bids of 
an opponent are above $b_{2}, B\left(b_{2}\right)=H_{2}\left(u_{2}\left(b_{2}\right)\right)-H_{1}\left(u_{1}\left(b_{2}\right)\right)$ is the probability that an opponent submits an introductory bid above and the successive bid below $b_{2}$, and $H_{1}\left(u_{1}\left(b_{2}\right)\right)$ is the probability that two bids of an opponent are below $b_{2}$. Note if the bidder uses the same strategy as his opponents, then $u_{2}\left(b_{2}\right)=v_{2}$, and if the opponents bid the introductory value in the introductory bid $u_{1}\left(b_{2}\right)=b_{2}$. Then $P_{k}(\cdot)$ is independent of the opponent strategy $b_{-}(\cdot)$ and that is why payoff can be expressed just a function of $b_{2}$ and $v_{2} .8$

Therefore, without loss of generality, I consider the successive equilibrium strategy that is independent of the introductory value

$$
b_{2}\left(v_{1}, v_{2}, R\right)=b_{2}\left(v_{2}, R\right) \text { for } v_{2} \in\left[R, \bar{v}_{2}\right], b_{2}\left(v_{1}, v_{2}, R\right)=0 \text { for } v_{2} \in[0, R) .
$$

Now I discuss a sufficient condition on the distribution of a bidder's values that guarantees that every symmetric equilibrium strategy is continuous.

Example 5. Let us take the same setting as in Example 3 in the case $R=0$ and $\bar{v}=1$. Then the successive equilibrium strategy (3.1) simplifies to $b_{2}\left(v_{2}\right)=$ $v_{2}^{2}$ for $v_{2} \in[0,1]$. Let us consider any weakly increasing strategy $b_{2}^{\prime}(\cdot)$ that is the same as $b_{2}(\cdot)$ for $v \in\left[0, v_{2}\right]$ and at $b_{2}$ jumps up from $v_{2}^{2}$ to $\check{b}$. Then for any $b_{2} \in\left[v_{2}^{2}, \check{b}\right]$ the difference in payoff is $\pi\left(v_{1}, b_{1}, v_{2},, b_{2}\right)-\pi\left(v_{1}, b_{1}, v_{2}, v_{2}^{2}\right)$ is $-\left(b_{2}-v_{2}^{2}\right) \cdot\left(1-H_{2}\left(v_{2}\right)\right)$ negative. It means that if the opponent uses this strategy, payoff of the bidder strictly decreases for $b_{2} \in\left[b_{2}\left(v_{2}\right), \check{b}\right]$. The reason is that $b_{2}$ increases the price the bidder pays for the introductory unit if $b_{2}$ is the first rejected bid and does not increase the probability of winning. Such a bid $b_{2}$ will defeat opponent's successive bid with the same probability as $b_{2}\left(v_{2}\right)$. The reason for this is that the opponent uses a strategy with a jump and although $b_{2}$ defeats opponent's introductory bid more often, the probability that $b_{2}$ is a winning bid is not changed. Therefore the bidder prefers to bid 
$b_{2}\left(v_{2}\right)$ than to bid $b_{2}$. For $v_{2}+\delta$ where $\delta$ is small and positive the jump cannot occur because payoff is continuous in $v_{2}$.

When the payoff is differentiable, then the marginal payoff is $\frac{\partial \pi\left(v_{2}, b_{2}\right)}{\partial b_{2}}$ and it is 0 if $b_{2}$ is the best response. If for some $v_{2}$ the opponent's strategy jumps from $\hat{b}=b_{2}\left(v_{2}^{-}\right)$to $\check{b}=b_{2}\left(v_{2}^{+}\right)$, then $\pi\left(v_{2}, \hat{b}\right)=\pi\left(v_{2}, \check{b}\right) \geq \pi\left(v_{2}, b\right)$ for any $b \in(\hat{b}, \breve{b})$ because the payoff is continuous in a successive value (see Lemma 8 in the Appendix). Therefore the relevant condition for a continuous equilibria is:

Condition C2. For any $v_{2} \in\left(R, \bar{v}_{2}\right)$ and any $b_{2} \in\left(R, v_{2}\right)$

$\frac{\partial \pi\left(v_{2}, b_{2}\right)}{\partial b_{2}}=\left(v_{2}-b_{2}\right) \frac{\partial P_{k-1}\left(b_{2}, v_{2}\right)}{\partial b_{2}}-P_{k}\left(b_{2}, v_{2}\right)+P_{k-1}\left(b_{2}, v_{2}\right) \leq 0$.

Lemma 5. Let there be more than two units for sale and condition C2 holds, then in any symmetric equilibrium any successive bid between the two best response bids is also the best response bid. In addition, if the inequality (4.4) is strict, then every symmetric equilibrium strategy is continuous.

For the formal proof of the lemma see in the Apendix and let me show some distributions that satisfy condition $\mathrm{C} 2$ :

1. If exactly one bid does not win when all bids are above the reservation price $(k=2 n-1)$ and $h_{1}(\cdot)>0$, then $\mathrm{C} 2$ is valid and every equilibrium strategy is continuous.

2. For $k=3, n \geq 2$ the condition (4.4) is simple:

$$
\begin{aligned}
& \left(v_{2}-b_{2}\right)(n-2) h_{1}\left(b_{2}\right)\left(H_{2}\left(v_{2}\right)-H_{1}\left(b_{2}\right)\right) \\
\leq & \left(1-H_{2}\left(v_{2}\right)\right) H_{1}\left(b_{2}\right)+\frac{n-2}{2}\left(H_{2}\left(v_{2}\right)-H_{1}\left(b_{2}\right)\right)^{2},
\end{aligned}
$$

that can be easily satisfied if $2 h_{1}\left(b_{2}\right) \leq h_{2}\left(b_{2}\right)$ and $h_{2}\left(b_{2}\right)$ is weakly increasing. 3

\footnotetext{
${ }^{3}$ For $n \rightarrow \infty$ large the condition simplifies to $2 g_{1}\left(b_{2}\right) \leq \frac{H_{2}\left(v_{2}\right)-H_{1}\left(b_{2}\right)}{v_{2}-b_{2}}$. Next realize that by
} 
3. For $k=2 n-3 \geq 3$ the condition is:

$$
\begin{aligned}
& \left(v_{2}-b_{2}\right) h_{1}\left(b_{2}\right)\left(H_{2}\left(v_{2}\right)-H_{1}\left(b_{2}\right)\right) \\
\leq & H_{1}\left(b_{2}\right)\left(1-H_{2}\left(v_{2}\right)\right)+\frac{n-2}{2}\left(H_{2}\left(v_{2}\right)-H_{1}\left(b_{2}\right)\right)^{2} .
\end{aligned}
$$

If $n \geq 4$ then the sufficient condition is that $h_{1}(\cdot)$ is weakly increasing.

The following density function satisfies all cases examples above

$$
h\left(v_{1}, v_{2}\right)=\left\{\begin{array}{c}
\frac{2 v_{2}}{v_{1}^{2}} \text { for } 0 \leq v_{2} \leq v_{1} \leq \frac{1}{2} \\
8 v_{2} \text { for } 0 \leq v_{2} \leq \frac{1}{2}, \frac{1}{2} \leq v_{1} \leq 1 \\
0 \text { otherwise }
\end{array}\right\} \Rightarrow \begin{aligned}
& H_{1}\left(b_{2}\right)=b_{2} \text { for } b_{2} \in[0,1] \\
& H_{2}\left(v_{2}\right)=2 v_{2} \text { for } v_{2} \in\left[0, \frac{1}{2}\right]
\end{aligned} .
$$

In the following example I illustrate the intuition behind the fact that the continuous successive equilibrium strategy is unique.

Example 6. Let us take the same setting as in Example 5 and consider how the equilibrium best response $b_{2}(\cdot)$ changes when the opponent changes its strategy $b_{-2}(\cdot)$. Assume that the opponent uses another continuous strategy that is above $b_{-2}(\cdot)$ in the right neighborhood of some $\hat{v} \in(0,1)>0$, e.g. for some $a>0$

$$
b_{-2}^{\prime}\left(v_{2}\right)=\left\{\begin{array}{cr}
b_{-2}\left(v_{2}\right)=v_{2}^{2} & \text { for } v_{2} \in[0, \hat{v}] \\
a \cdot\left(v_{2}-\hat{v}\right)+\hat{v}^{2} & \text { for } v_{2} \in(\hat{v}, \hat{v}+\delta] \\
\text { any other weakly increasing strategy } & \text { for } v_{2} \in(\hat{v}+\delta, 1] .
\end{array}\right.
$$

Then the marginal pay-off is

$$
\frac{\partial \pi\left(v_{2}, b_{2}\right)}{\partial b_{2}}=\left(v_{2}-b_{2}\right) \cdot \frac{2}{a}\left(1-\frac{b_{2}-\hat{v}^{2}}{a}-\hat{v}\right)-\left(1-\frac{b_{2}-\hat{v}^{2}}{a}-\hat{v}\right)^{2} .
$$

It is negative for $a \in[2 \cdot \hat{v}, \infty), b_{2} \in\left[\hat{v}^{2}, \hat{v}^{2}+a \cdot \delta\right]$ and $v_{2} \in\left[\hat{v}, \hat{v}+\min \left(\hat{v}^{2}, \delta\right)\right)$. Therefore if the opponent increases his strategy on the right neighborhood of the mean value theorem for some $\tilde{b} \in\left[b_{2}, v_{2}\right] \frac{H_{2}\left(v_{2}\right)-H_{1}\left(b_{2}\right)}{v_{2}-b_{2}}=\frac{H_{2}\left(v_{2}\right)-H_{2}\left(b_{2}\right)}{v_{2}-b_{2}}+\frac{H_{2}\left(b_{2}\right)-H_{1}\left(b_{2}\right)}{v_{2}-b_{2}}=$ $\frac{H_{2}\left(b_{2}\right)-H_{1}\left(b_{2}\right)}{v_{2}-b_{2}}+h_{2}(\tilde{b})$. 
$\hat{v}$, then the bidder's best response must be constant on the right neighborhood of $\hat{v}$ or discontinuous at $\hat{v}$. Hence no opponent strategy above $b_{-2}(\cdot)$ yields a symmetric best response. Similarly for $a \in(0,2 \cdot \hat{v}), v_{2} \in(\hat{v}, \hat{v}+\delta)$, and $b_{2} \in\left[\hat{v}^{2}, \hat{v}^{2}+\min (((2 \hat{v}-a)(1-\hat{v})), a \cdot \delta)\right]$ the marginal pay-off (4.5) is positive. Therefore if the opponent decreases his strategy on the right neighborhood of $\hat{v}$, then the bidder' best response must jump to $\hat{v}$.

A similar mechanic is present in the single-unit, pay-your-bid auction (see e.g. Lizzeri and Persico (2000)). The following theorem, which is proved in the Appendix shows that if one is sure that the equilibrium strategy is continuous (or the payoff is constant in jumps), then the two equilibrium strategies cannot cross.

Theorem 1. Let there be more than two units for sale, condition C2 holds, and bidders use $b_{1}\left(v_{1}, v_{2}, R\right)=v_{1}$, then for any value $v_{2}$ and bid $\hat{b}$ such that $\bar{v} \geq v_{2}>\hat{b} \geq R \geq 0$ there is at most one symmetric equilibrium strategy going through point $\left[v_{2}, \hat{b}\right]$.

The intuitive reason of why the two continuous strategies cannot cross generalizes Example 6. Consider any two symmetric weakly increasing successive strategies $b_{2}(\cdot)$ and $\bar{b}_{2}(\cdot)$ that are different on the left neighborhood of $v_{2}$ and such that $\hat{b}=\lim _{v^{\prime} \rightarrow v_{2}^{-}} b_{2}\left(v^{\prime}\right)=\lim _{v^{\prime} \rightarrow v_{2}^{-}} \bar{b}_{2}\left(v^{\prime}\right)$ where $\bar{v} \geq v_{2}>\hat{b} \geq R$. Let me denote the lower strategy on the left neighborhood of $v_{2}$ as $\bar{b}_{2}(\cdot)$ and without loss of generality I assume that it is a symmetric equilibrium. It is sufficient to show that if opponents employ strategy $b_{2}(\cdot)$, then the bidder prefers to bid $b_{2}\left(v_{2}\right)$ than $b_{2}\left(v_{2}-\delta\right)$ for values $v_{2}-\delta$ slightly below $v_{2}$ for positive small enough $\delta$. When the opponents use the strategy $b_{2}(\cdot)$ instead of $\bar{b}_{2}(\cdot)$, the probability that bidder $i$ wins the successive unit is higher on the left neighborhood of $b_{2}\left(v_{2}\right)$. Also the price paid in the auction increases on the left neighborhood of $b_{2}\left(v_{2}\right)$ but the effect on price is much smaller and the bidder 
prefers to bid $b_{2}\left(v_{2}\right)$ instead of $b_{2}\left(v_{2}-\delta\right)$ for values $v_{2}-\delta$. Therefore no opponent strategy above $\bar{b}_{2}(\cdot)$ on the left neighborhood of $v_{2}$ enforces a symmetric best response of the bidder. Similar logic can be used to show that no two strategies emerge from $\left[v_{2}, \hat{b}\right]$ (see the proof in the Appendix for more details). The case $k=2$ has been deeply analyzed in Engelbrecht-Wiggans and Kahn (1998). They show examples with many symmetric continuous equilibria.

Corollary 2. If $k=2 n-1$, then the successive equilibrium strategy is continuous and unique.

One simple implication of Lemma 1 is that the reservation price increases any continuous equilibrium strategy.

Theorem 2. Assume that $n \geq 3, k=3, \cdots, 2 \cdot n-3$, and conditions $C 1$ and $C 2$ are valid or $k=2 \cdot n-1 \geq 3$. Consider two symmetric equilibrium strategies $b_{2}\left(v_{2}, R\right)$ and $b_{2}\left(v_{2}, R^{\prime}\right)$ for different reservation prices $R^{\prime}>R \geq 0$. Then $b_{2}\left(v_{2}, R^{\prime}\right)>b_{2}\left(v_{2}, R\right)$ for any $v_{2} \in\left[R^{\prime}, \bar{v}\right]$.

Proof. Since bidders bid strictly below their value above the reservation price (see Lemma 6 in the Appendix), it must be that $b_{2}\left(R^{\prime}, R\right)<R^{\prime}$. Moreover $R^{\prime}=b_{2}\left(R^{\prime}, R^{\prime}\right)$, and for $v_{2}>R^{\prime}$, the two continuous equilibrium strategies cannot cross according to Theorem 1.

Q.E.D.

Examples 2 and 4 show that in some cases when $R=0$ bidders may use equilibrium in that they bid $b_{2}\left(v_{2}\right)=0$ for positive measure zero of values (see also Engelbrecht-Wiggans and Kahn (1998), and Ausubel and Cramton (2004)). But Lemma 1 shows that such behavior disappears if the seller sets a positive reservation price because it affects both the introductory and successive strategy as is illustrated in the following example. 
Example 7. Let me continue with Example 4. Imagine the seller sets a positive reservation price. In equilibrium, the introductory bid strategy is to bid below $R$ if $v_{1}$ is below $R$. By Theorem 1, the successive strategy is strictly increasing for $v_{2}>R$ and therefore $b_{2}\left(\bar{v}_{2}, R\right)>R$ and by Lemma 4 the bidders bid their introductory value for $v_{1} \in\left(R, b_{2}\left(\bar{v}_{2}, R\right)\right)$.

The reservation price forces bidders to bid strictly above the reservation price if their value is above the reservation price. Moreover, since the two strategies cannot cross it increases the strategy and improves revenue to the seller. The multi-unit element can motivate bidders to bid at 0 with positive probability, but the positive reservation prices eliminate such behavior. In addition, it increases the bidder's strategy and, hence, revenue to the seller. These "well-behaved" features are typical for single-unit auctions. Moreover, the reservation price may improve the allocation efficiency of auctioned units.

It is a question of future research to what extent are these effects present if the bidders submit more than two bids or in other multi-unit auction types. In the uniform-price auction when bidders submit more than two bids the bidders $j$ th bid can influence the price of his $j-1$ units of the bidder and $j+1$ st bid can influence the price of one more of his units. It seems the bidder has an incentive to decrease his bid more on the $j+1$ st unit than on his $j$ th unit even if the values on the $j$ th and the $j+1$ st unit are the same. Then in equilibrium the bidders submitted bids are such that $b_{j}>b_{j+1}$. Therefore, if the strategies on the other than $j$ th unit are the same the two strategies on the $j$ th unit cannot cross and the reservation price increases the bidder strategy as well and, hence, the seller's revenue.

Finally, the following example illustrates that the reservation price can prevent some kind of collusion of the bidders in repeated games.

Example 8. Consider the auction game of Example 4 with $n=k=4$ but assume that bidders use the following asymmetric strategies. In every even 
game two bidders submit $b_{2}=b_{1}=\bar{v}_{1}$ and the other two bidders bid 0 . In every odd game the two bidders swap their bidding strategies with the other two bidders.

In each auction round the bidders who bid 0 have no incentive to deviate because for any other strategy their payoff is nonpositive. But if the seller sets $R>0$ and the bidders use the same strategy, the bidders with values below $R$ have incentive to bid below $R$ in each round. But if they do so, then the two opponents with a value above $R$ who bid 0 have incentive to bid above $R$. Therefore in each round it is less likely that the auction price is $R$ with a probability 1 .

\section{Conclusion}

The reservation price and the maximum number of submitted bids of each bidder are essential policy tools of the uniform-price auction game. When these two tools are applied in the auction, the bidders' strategic behavior is more similar to the one in single-unit auctions.

In a uniform-price auction the bidders often reveal their true value in their introductory unit bid similarly as in the second-price auction. It is a consequence of the fact that the introductory bid influences only the probability of winning and not the price the bidder pays in an auction. When bidding on successive units in a uniform-price auction a bid increase has positive effect on the probability of winning the unit and the price paid for the introductory unit when the bid is the first-rejected one. In addition, when opponents change their equilibrium strategy, the effect on price is less significant than the effect on the probability of winning. Similar reasoning can be applied for a singleunit pay-your-bid auction except for the fact that a bid influences the price of the unit it is submitted for. This analogy means that bidders bid higher when they have higher value or the reservation price is higher similarly as in the single-unit auctions (see McAfee and McMillan (1987), Lizzeri and Persico 
$(2000))$.

But this dependence is not the same for bids on all units for sale. Bids on higher sold units influence the price paid for more predecessor units. Therefore the effect on the price of higher unit bids seems to be much more significant than the effect on the probability of winning. Therefore the equilibrium strategies that are less favorable to the seller occur more often in the set of symmetric equilibrium strategies.

When each bidder is restricted to submit no more than $\left\lceil\frac{k}{2}\right\rceil$ units for sale, the bidders use strategies that are strictly increasing above the reservation price, and the effect on the seller's revenue may not be significant because the bids on $\left\lceil\frac{k}{2}\right\rceil+1$ st and higher units are low anyway. The two mutually crossing strategies are not the best responses (at least if each bidder submits two bids). A consequence of this is that the reservation price increases the symmetric equilibrium strategy.

Next, when the seller does not limit the bidders to submit a certain number of bids and does not set a reservation price, the bidders have a tendency to bid 0 on the successive unit with positive probability. Then a positive reservation price increases the bidders successive strategy and gives the bidders an incentive to increase their bids strictly above the reservation price. Therefore, the revenue to the seller increases. In addition, other studies (Ausubel and Cramton (2002), Palfrey (1983)) show that the allocation of units is not efficient in the uniform-price auction (the units are not allocated to those bidders who value them most). If one treats the reservation price as additional bids, the higher reservation price may improve not only the revenue but also efficiency. This effect might be important in the case of small number of bidders. Example 8 shows that positive reservation price improves the strategic behavior in repeated auction games.

Applying a reservation price and a maximum number of bids restriction 
facilitates bidders' equilibrium behavior that the seller prefers and that are "common" for single-unit auctions. The seller who uses these two policy tools can improve the uniform-price auction significantly both from his and the social welfare point of view. 


\section{Appendix}

Proof of lemma 1. Consider the restricted game defined in Section 2 when each bidder can submit $l$ bids. Now consider another game $G$ in which each bidder can submit $k$ bids. Let us assume that the distribution of values $v_{j}$ for $j=1, \cdots, l$ of each bidder is the same as in the restricted game from Section 2 and value $v_{j}$ is below the reservation price for $j=l+1, \cdots, k$. In addition, assume that each bidder $i$ pays a penalty fee when not revealing his true value in his introductory bid, therefore his ex post payoff $\hat{\pi}_{i}\left(v_{i}, b_{i}, c, R\right)$ is decreased by the fee $\left|v_{i, 1}-b_{i, 1}\right|$ if he wins an introductory value. Note that with this modified payoff the bidder is worse off if he bids $b_{i, 1}(v, R) \neq v_{i, 1}$ instead of $b_{i, 1}(v, R)=v_{i, 1}$ (cf. with the standard features of single-unit second-price auction). Then by Bresky (1999) a pure strategy equilibrium $m$ of the game $G$ exists in that bidders bid $b_{j}$ below the reservation price for $j=l+1, \cdots, k$ and reveal their true value in the introductory bid. Now it is easy to check that $m$ is an equilibrium in the restricted game defined in Section 2. First note that the seller does not satisfy the bids below the reservation price that have the same effect on the strategic consideration of the bidders in the restricted game where the seller does not accept these bids. Next, realize that if the penalty is removed from an introductory bid by standard argumentation of single-unit second-price auction, then the bidder is no better off if he bids $b_{i, 1}(v, R) \neq v_{i, 1}$ instead of $b_{i, 1}(v, R)=v_{i, 1}$.

Q.E.D.

Proof of lemma 2. If $b_{j}$ is equal to $k+1-j$ th highest opponent bid with positive probability and the bidder bids $b_{j}+\varepsilon\left(\right.$ or $\left.b_{j}-\varepsilon\right)$ for tied values $v_{j}>b_{j}$ (or $v_{j}<b_{j}$ ) and also for values slightly above (or below) the tied values, he increases the payoff. The reason is that if the tie occurs, he is strictly better off and if his bid $b_{j}+\varepsilon$ (or $\left.b_{j}-\varepsilon\right)$ is the first rejected bid the price change can be made arbitrarily small. Moreover, for $\varepsilon$ sufficiently small the set of values 
above the tied values for that he bids $b_{j}+\varepsilon$ has almost measure 0 having negligible effect on payoff.

Q.E.D.

Proof of corollary 1. If any bidder bids above $R$ on a value not above $R$, he may win and gets negative ex post payoff because the auction price is at least $R$. Therefore using the condition $\mathrm{C} 1$ no bidder does so in equilibrium because if all bidders have values which are not above $R$ and some of them bids above $R$, then at least some of these win and can improve when bidding below $R$. Similarly if any bidder bids below $R$ or $R$ on a value above $R$, then he may be better off when bidding above $R$ because he gets a positive pay off with positive probability.

Consider an equilibrium in which two bidders 1 and 2 bid $R$ with positive probability on the $j$ th unit $(j=2, \cdots, l)$ having the value above $R$. Then their bids $b_{1,1}, \cdots b_{1, j-1}, b_{2,1}, \cdots b_{2, j-1}$ are not below $R$ and bids $b_{1, j+1}, \cdots, b_{1, l_{j}}$, $b_{2, j+1}, \cdots, b_{2, l_{j}}$ are not above $R$. Using the assumption $\mathrm{C} 1$ there is a positive probability that exactly $k-\left(j_{1}-1\right)-\left(j_{2}-1\right)-1$ opponents' values, and hence the bids, are above $R$ when $R>0$. This implies that $b_{1, j_{1}-1}$ and $b_{2, j_{2}}$ are tied and it cannot occur in equilibrium by Lemma 2 .

Q.E.D.

Lemma 6. If condition $C 1$ is valid and $2 \leq k<2 n$, then in any symmetric equilibrium for any $v_{2} \in\left(R, \bar{v}_{2}\right)$, the best response $b_{2}\left(v_{2}\right) \in\left(R, v_{2}\right)$.

Proof.For any value $v_{2} \in\left(R, \bar{v}_{2}\right)$ it is obvious that bidding slightly above $R$ is better than bidding below $R$. Moreover by Lemma 1 bidding above $R$ is better than bidding at $R$ otherwise there is a tie at $R$ above 0 . Then for any successive value $v_{2} \in\left[b_{2}\left(\bar{v}_{2}\right), \bar{v}_{2}\right)$ the statement of the lemma is trivial because $b_{2}(\cdot)$ is increasing. 
It remains to check that for any $v_{2} \in\left(R, b_{2}\left(\bar{v}_{2}\right)\right)$ the best response is below $v_{2}$. By the way of contradiction assume that a bidder bids $v_{2}$ in equilibrium and consider the sequence of bids $b_{2} \rightarrow v_{2}^{-}$from below such that there is no tie when bidding $b_{2}$ along the sequence. Such a sequence exists because there is at most countably many mass points in the opponents bid distribution. For bids $b_{2}>R$ along this sequence substitute (2.5) into

$$
\begin{gathered}
\frac{\pi\left(v_{1}, v_{2}, b_{1}, v_{2}\right)-\pi\left(v_{1}, v_{2}, b_{1}, b_{2}\right)}{v_{2}-b_{2}}= \\
-\left(P_{k-1}\left(b_{2}\right)\right)-\frac{\int_{b_{2}}^{v_{2}} P_{k}\left(c_{k}\right) d c_{k}}{v_{2}-b_{2}}+2 \cdot \frac{\int_{b_{2}}^{v_{2}} P_{k-1}\left(c_{k-1}\right) d c_{k-1}}{v_{2}-b_{2}}
\end{gathered}
$$

In the limit as $b_{2} \rightarrow v_{2}^{-}$one gets

$$
\begin{gathered}
\lim _{b_{2} \rightarrow v_{2}^{-}} \frac{\partial \pi\left(b_{2}\right)}{\partial b_{2}}=P_{k-1}\left(v_{2}\right)-P_{k}\left(v_{2}\right)= \\
=\sum_{\substack{2 i_{2}+i_{1}=k-1, 0 \leq i_{2}, i_{1} \leq n-1}} \frac{(n-1) !}{i_{2} ! i_{1} !\left(n-1-i_{2}-i_{1}\right) !} A^{i_{2}}\left(b_{2}\right) B^{i_{1}}\left(b_{2}\right) H_{1}^{n-1-i_{1}-i_{2}}\left(u_{1}\left(b_{2}\right)\right) .
\end{gathered}
$$

The summation term in the equation (6.1) is the probability that the bidder's successive bid is the $k$ th highest bid from all submitted bids. I show that this probability is positive for any successive value $v_{2}$ from $\left(R, b_{2}\left(\bar{v}_{2}\right)\right)$. For any $v_{2} \in\left(R, b_{2}\left(\bar{v}_{2}\right)\right)$ there is a positive probability that any introductory bid is above $v_{2}$ or below $v_{2}$ by Lemma 3 and 4 . In addition, there is positive probability that any successive bid is below or above $v_{2}$. Then all factors of the summation term are positive that finishes the proof.

Q.E.D.

Proof of Lemma 3. During the proof the statements are valid up to a measure zero set. Let me consider an introductory equilibrium strategy in which $v_{1}>b_{1}$ for a positive measure set of values. Consider opponent bids assuming that opponent introductory values are between $b_{1}, v_{1}$. If the lowest of the opponent's introductory bids is below $b_{1}$, then the opponent can improve 
upon his payoff by bidding his introductory value. When all opponents do so, $b_{1}$ is losing and the bidder can improve upon his payoff by bidding above the opponent highest introductory bid (but not above his introductory value). Since this is true for all opponent introductory values arbitrarily close to $v_{1}$, the bidder cannot bid below $v_{1}$.

Similarly if $b_{1}>v_{1}$, opponent introductory values are between $b_{1}$ and $v_{1}$, opponent winning (introductory and successive) bids cannot be above $b_{1}$ in equilibrium otherwise the bidders prefer to decrease bids. Since according to the previous paragraph, opponents do not bid below their introductory value $b_{1}$ is a winning bid and the bidder pays the price above $v_{1}$. But then the bidder with value $v_{1}$ prefers to bid below the lowest opponent's introductory bid (but not below his introductory value). Since it is true for opponent introductory values arbitrarily close to $v_{1}$, the bidder cannot bid above his value. Therefore $b_{1}=v_{1}$.

$$
\text { Q.E.D. }
$$

Proof of Lemma 4. Consider the $n-\left\lfloor\frac{k}{2}\right\rfloor$ bidders' introductory values below $\bar{b}_{2}$. Using C1 fix the successive bids of other $\left\lfloor\frac{k-1}{2}\right\rfloor$ bidders above the highest of the $n-\left\lfloor\frac{k-1}{2}\right\rfloor$ bidders' introductory values and if $k$ is even, fix the introductory value of one bidder above the highest of the $n-\left\lfloor\frac{k-1}{2}\right\rfloor$ bidders' introductory values and his successive value below the lowest of the $n-\left\lfloor\frac{k-1}{2}\right\rfloor$ bidders' introductory values. Now repeat the same arguments as in Lemma 3 to show that the group of $n-\left\lfloor\frac{k-1}{2}\right\rfloor$ bidders must reveal their introductory value in their introductory bid. Realize that $n-\left\lfloor\frac{k-1}{2}\right\rfloor \geq 2$ bidders compete for one unallocated unit when the bids fixed close to $\bar{b}_{2}$ win.

If $b_{2}(\cdot)$ is continuous and $k \leq 2 \cdot n-1$, then $n-\left\lfloor\frac{k-1}{2}\right\rfloor=1$ bidder competes for one not allocated unit with the opponent successive bids.

Q.E.D. 
Lemma 7. For any $v_{2} \in\left(R, \bar{v}_{2}\right]$ the set of successive best responses is the same for any $v_{1} \in\left[v_{2}, \bar{v}_{1}\right]$. The successive strategy can be characterized by (4.3).

Proof. Consider $v_{2} \in\left(R, \bar{v}_{2}\right]$ with two different $v_{1}$ and $v_{1}^{\prime}$ above $v_{2}$. Using similar arguments as in Lemma 3 and 4, the bidder cannot submit a successive bid strictly above his successive value in symmetric equilibrium.

From Lemma 6 any best response satisfies $v_{2}>b_{2}$. By the formula in Lemma 1 we can see that the set of choices for $b_{2}$ which maximize the bidder's payoff is independent of the introductory value because $\min \left(b_{1}, b_{1}^{\prime}\right)=$ $\min \left(v_{1}, v_{1}^{\prime}\right) \geq v_{2}>b_{2}$. Since bidders use weakly increasing strategies the best response may not be unique only in jumps. There is at most countably many jumps and therefore $b_{2}$ is independent of $v_{1}$ up to a measure zero subset.

Q.E.D.

Lemma 8. Assume that $h_{2}\left(v_{2}\right)>0$ for $v_{2} \in\left(0, \bar{v}_{2}\right)$ almost surely. For any given opponent strategy denote $b_{2}(\cdot)$ as the best response of the bidder if it exists. Then the pointwise best response payoff is a continuous function of successive value

$$
\lim _{w \rightarrow v_{2}^{+}} \pi\left(v_{1}, w, b_{1}, b_{2}(w)\right)=\lim _{w \rightarrow v_{2}^{-}} \pi\left(v_{1}, w, b_{1}, b_{2}(w)\right)=\pi\left(v_{1}, v_{2}, b_{1}, b_{2}\left(v_{2}\right)\right)
$$

and no bid $b$ is a better response than $b_{2}\left(v_{2}\right)$

$$
\pi\left(v_{1}, v_{2}, b_{1}, b_{2}\left(v_{2}\right)\right) \geq \pi\left(v_{1}, v_{2}, b_{1}, b\right) \text { for any } b \in[0, \infty) .
$$

Proof. At first note that $\lim _{w \rightarrow v_{2}^{-}} \pi\left(v_{1}, w, b_{1}, b_{2}(w)\right) \leq \pi\left(v_{1}, v_{2}, b_{1}, b_{2}\left(v_{2}\right)\right) \leq$ $\lim _{w \rightarrow v_{2}^{+}} \pi\left(v_{1}, w, b_{1}, b_{2}(w)\right)$ because if the bidder bids the same for two different successive values, his expected payoff is higher for the higher value. Therefore the best response payoff from some value is at least as high as the best response payoff from any value below. 
By contradiction, assume that $\lim _{w \rightarrow v_{2}^{+}} \pi\left(v_{1}, w, b_{1}, b(w)\right)<\pi\left(v_{1}, v_{2}, b_{1}, b\right)$ for some $b \in[0, \infty)$. Then if a bidder with value $v_{2}+\delta$ submits bid $b$, his payoff is almost the same as $\pi\left(v_{1}, v_{2}, b_{1}, b\right)$ for sufficiently small $\delta>0$ because payoff is continuous in $v_{2} \cdot{ }^{4}$ The proof is the same for $w \rightarrow v_{2}^{-}$up to the fact that $\delta<0$. That completes the proof of the equality (6.2) and also (6.3) is obvious.

Q.E.D.

Proof of lemma 5. Consider the symmetric equilibrium strategy $b_{2}(\cdot)$. Assume that there is a jump at $v_{2}$ from $\hat{b}=\lim _{w \rightarrow v_{2}^{-}} b_{2}(w), \check{b}=\lim _{w \rightarrow v_{2}^{+}} b_{2}(w)$. Since there are no ties, if the opponents play equilibrium strategy, the distribution of $k-1$ st highest opponent bid is continuous weakly increasing and therefore differentiable almost everywhere that implies differentiability of the payoff.

Payoff from bidding any $b_{2} \in[\hat{b}, \check{b}]$ can be expressed as

$$
\pi\left(v_{2}, b_{2}\right)=\int_{\hat{b}}^{b_{2}} \frac{\partial \pi\left(v_{2}, c\right)}{\partial b_{2}} d c+\pi\left(v_{2}, \hat{b}\right) .
$$

In symmetric equilibrium $v_{2}=u_{2}\left(b_{2}\right)$ and therefore $\frac{\partial u_{2}\left(b_{2}\right)}{\partial b_{2}}=0$ that implies $P_{k}\left(b_{2}\right)-P_{k-1}\left(b_{2}\right)=P_{k}\left(b_{2}, v_{2}\right)-P_{k-1}\left(b_{2}, v_{2}\right)$ and $\frac{\partial P_{k-1}\left(b_{2}\right)}{\partial b_{2}}=\frac{\partial P_{k-1}\left(b_{2}, u_{2}\right)}{\partial u_{2}} \frac{\partial u_{2}\left(b_{2}\right)}{\partial b_{2}}+$ $\frac{\partial P_{k-1}\left(b_{2}, u_{2}\right)}{\partial b_{2}}=\frac{\partial P_{k-1}\left(b_{2}, u_{2}\right)}{\partial b_{2}}$. Hence (4.4) implies that $\frac{\partial \pi\left(v_{2}, c\right)}{\partial b_{2}} \leq 0$. Since by Lemma $8 \pi\left(v_{2}, \hat{b}\right)=\pi\left(v_{2}, \check{b}\right)$, it must be that $\int_{\hat{b}}^{b_{2}} \frac{\partial \pi\left(v_{2}, c\right)}{\partial b_{2}} d c=0$ which completes the first part of the Lemma. Moreover if the inequality (4.4) is strict, then $\frac{\partial \pi\left(v_{2}, c\right)}{\partial b_{2}}<0$ and therefore $\check{b}=\hat{b}$.

Q.E.D.

Proof of Theorem 1. Consider any two symmetric weakly increasing successive strategies $b_{2}(\cdot)$ and $\bar{b}_{2}(\cdot)$ that are different on the left neighborhood of $v_{2}$ and such that $\hat{b}=\lim _{w \rightarrow v_{2}^{-}} b_{2}(w)=\lim _{w \rightarrow v_{2}^{-}} \bar{b}_{2}(w)$ where $\bar{v}>v_{2}>\hat{b} \geq R$.

\footnotetext{
${ }^{4}$ Since $h_{2}\left(v_{2}+\delta\right)>0$ for $v_{2}+\delta$ the bidder could have been strictly better off for a positive measure of subsequent values.
} 
Let me denote the lower strategy on the right neighborhood of $v_{2}$ as $\bar{b}_{2}(\cdot)$ and without loss of generality I assume that it is a symmetric equilibrium. I show that if opponents employ strategy $b_{2}(\cdot)$, then the bidder prefers to bid $b_{2}\left(v_{2}\right)$ than $b_{2}\left(v_{2}-\delta\right)$ for values $v_{2}-\delta$.

Since $k>2$ then there cannot be mass points in the distribution of opponent bids by Lemma 2 . To simplify the notation, I will write $b_{2}$ instead of $b_{2}\left(v_{2}-\delta\right)$. Consider the following inequality $0<\bar{\pi}\left(v_{2}-\delta, b_{2}\right)-\bar{\pi}\left(v_{2}-\delta, \hat{b}\right)$. If it is true for all $\delta \in\left(0, \Delta_{0}\right)$ for some $\Delta_{0}>0$, then no strategy below $b_{2}$ is the best response including $\bar{b}_{2}\left(v_{2}-\delta\right) .^{5}$

Therefore it must be that

$0 \geq \bar{\pi}\left(v_{2}-\delta, b_{2}\right)-\bar{\pi}\left(v_{2}-\delta, \hat{b}\right)=\bar{\pi}\left(v_{2}, b_{2}\right)-\bar{\pi}\left(v_{2}, \hat{b}\right)-\delta \cdot\left(\bar{P}_{k-1}\left(b_{2}\right)-\bar{P}_{k-1}(\hat{b})\right)$

Let me show that the payoff difference from bidding $b_{2}$ and $\hat{b}$ decreases when the opponents use $b_{2}(\cdot)$ instead of $\bar{b}_{2}(\cdot)$

$$
\begin{gathered}
\bar{\pi}\left(v_{2}, b_{2}\right)-\bar{\pi}\left(v_{2}, \hat{b}\right)=\pi\left(v_{2}, b_{2}\right)-\pi\left(v_{2}, \hat{b}\right)+\left(v_{2}-b_{2}\right) \cdot\left(\bar{P}_{k-1}\left(b_{2}\right)-\bar{P}_{k-1}\left(b_{2}\right)\right) \\
+2 \int_{b_{2}}^{\hat{b}}\left(\bar{P}_{k-1}(c)-P_{k-1}(c)\right) d c-\int_{b_{2}}^{\hat{b}}\left(\bar{P}_{k}(c)-P_{k}(c)\right) d c
\end{gathered}
$$

Since $P_{k}, P_{k-1}, \bar{P}_{k}, \bar{P}_{k-1}$ are weakly increasing functions the integrals can be approximated by

$$
2 \cdot\left(b_{2}-\hat{b}\right) \cdot\left(\bar{P}_{k-1}\left(b_{2}\right)-P_{k-1}\left(b_{2}\right)\right)-\left(b_{2}-\hat{b}\right) \cdot\left(\bar{P}_{k}\left(b_{2}\right)-P_{k}\left(b_{2}\right)\right) .
$$

Therefore, for $\delta$ close to $0, b_{2}$ is close to $\hat{b}$, and integrals are negligible with respect to the $\left(v_{2}-b_{2}\right) \cdot\left(\bar{P}_{k-1}\left(b_{2}\right)-P_{k-1}\left(b_{2}\right)\right)$ because $v_{2}>\hat{b}$ and $P_{k}(\cdot)$, $P_{k-1}(\cdot), \bar{P}_{k}(\cdot)$, and $\bar{P}_{k-1}(\cdot)$ are bounded functions. ${ }^{6}$ Therefore for $b_{2}$ slightly

\footnotetext{
${ }^{5}$ It implies that for all $\mu \geq \delta: 0<\bar{\pi}\left(v, b_{2}\right)-\bar{\pi}(\hat{v}, \hat{b})+\mu \cdot\left(\bar{P}\left(b_{2}\right)-P(\hat{b})\right)$.

${ }^{6}$ Note that $\left(v_{2}-b_{2}\right) \cdot \bar{P}_{k-1}\left(b_{2}\right)+2 \cdot\left(b_{2}-\hat{b}\right) \cdot \bar{P}_{k-1}\left(b_{2}\right)-\left(b_{2}-\hat{b}\right) \cdot \bar{P}_{k}\left(b_{2}\right)$ is approximately $\left(v_{2}-b_{2}\right) \cdot \bar{P}_{k-1}\left(b_{2}\right)$ because $\bar{P}_{k-1}\left(b_{2}\right)$ if $v_{2}>b_{2}$. Similarly for $P_{k-1}(\cdot), P_{k}(\cdot)$.
} 
above $\hat{b}(6.4)$ implies

$$
\begin{gathered}
0 \geq \pi\left(v_{2}, b_{2}\right)-\pi\left(v_{2}, \hat{b}\right)+\left(v_{2}-b_{2}\right)\left(\bar{P}_{k-1}\left(b_{2}\right)-P_{k-1}\left(b_{2}\right)\right)-\delta \cdot\left(P_{k-1}\left(b_{2}\right)-P_{k-1}(\hat{b})\right) \\
=\pi\left(v_{2}-\delta, b_{2}\right)-\pi\left(v_{2}-\delta, \hat{b}\right)+\left(v_{2}-b\right)\left(\bar{P}_{k-1}\left(b_{2}\right)-P_{k-1}\left(b_{2}\right)\right) .
\end{gathered}
$$

Since $\left(v_{2}-b_{2}\right)\left(\bar{P}\left(b_{2}\right)-P\left(b_{2}\right)\right)$ is positive for $\delta \in\left(0, \Delta_{0}\right)$ then $0>\pi\left(v_{2}-\delta, b_{2}\right)-$ $\pi\left(v_{2}-\delta, \hat{b}\right) \cdot{ }^{7}$ That contradicts the assumption that $b_{2}=b_{2}\left(v_{2}-\delta\right)$ is the best response because for positive measure values $v_{2}-\delta$ the bidder can improve upon his payoff. Therefore no opponent strategy above $\bar{b}_{2}(\cdot)$ on the left neighborhood of $v_{2}$ enforces a symmetric best response of the bidder. By Lemma $6 v_{2}>b_{2}\left(v_{2}\right) \geq R$ for $v_{2} \in(R, \bar{v})$ that implies that two symmetric continuous equilibrium strategies can touch only at $v_{2}=\hat{b}=\bar{v}$. Similar logic can be used to show that no two continuous strategies can emerge from any $\left[v_{2}, \hat{b}\right]$ except if $v_{2}=\hat{b}=R$.

Q.E.D.

Proof of Corollary 2. If $k=2 \cdot n-1$, then each bidder wins the introductory bid above reservation price unit surely using any strategy without ties because at most one submitted bid above the reservation price is not satisfied. Therefore for any such strategy, the bidders' payoff is the same as if they reveal their introductory value in an introductory bid. Then by Lemma 5 and the discussion below, the successive equilibrium strategy is continuous. Since the proof of Lemma 1 is valid even for $v_{2}=\hat{b}$ because $\bar{P}_{k}(c)=P_{k}(c)=1$, there is at most one continuous successive equilibrium strategy. Then by Lemma 4 for $v_{1} \in\left[R, b_{2}\left(\bar{v}_{2}\right)\right]$ introductory strategy is unique.

Q.E.D.

\footnotetext{
${ }^{7}$ Recall that $b(\hat{v})=\bar{b}(\hat{v})$ and $b(\hat{v}+\delta)>\bar{b}(\hat{v}+\delta)$ for positive small $\delta$.
} 


\section{Reference}

Ausubel, M. Lawrence, and Cramton C. Peter (2002). "Demand Reduction and Inefficiency in Multi-unit Auctions," Working Paper, University of Maryland.

Ausubel, M. Lawrence, and Cramton C. Peter (2004). "Vickrey Auctions with Reserve Pricing," Economic Theory, 23, 493-505.

Bresky, Michal (1999). "Equilibria in Multi-unit Auctions," Working Paper 145, CERGE-EI, Prague.

Billingsley (1968). Convergence of Probability and Measures, John Wiley and Sons, NY.

Draaisma, Teun and Charles Noussair (1997). "Optimal Bidding in a Uniform Price Auction with Multi-unit Demand," Economics Letters 56, 157-62.

Engelbrecht-Wiggans, Richard (1999). "An Example of Multi-unit Auctions with Atypically Many Equilibria," Economics Letters 65, 67-69.

Engelbrecht-Wiggans, Richard and Charles M. Kahn (1998). "Multi-unit Auctions with Uniform Prices," Economic Theory 12, 227-258.

Engelbrecht-Wiggans, Richard and Indranil Chakraborty (2005). "Asymptotic prices in uniform-price multi-unit auctions," Economic Theory 26(4), 983-987.

Jackson, Matthew, and Jeroen Swinkels (2005): "Existence of Equilibrium in Single and Double Private Value Auctions," Econometrica, 73(1), 93-139.

Lizzeri, Alesandro, and Nicola Persico (2000). "Uniqueness and Existence of Equilibrium in Auctions with a Reserve Price," Games and Economic Behavior, 30(1), 83-114.

McAfee, Preston R., and John McMillan (1987). "Auctions and Bidding," Journal of Economic Literature 25, 699-738.

Noussair, Charles (1995). "Equilibria in a Multi-object Uniform Price Sealed Bid Auction with Multi-unit Demands," Economic Theory 5, 337-351. 
Perry, Motty and Philip Reny (2002). "An Efficient Auction.," Econometrica, 70(3), 1199-1212.

Palfrey, Thomas (1983). "Bundling Decisions by a Multiproduct Monopolist with Incomplete Information," Econometrica 51(2), 463-483.

Reny, Philip, J. (1999). "On the existence of Pure and Mixed Strategy Nash Equilibria in Discontinuous Games," Econometrica 67, 1029-1056.

Swinkels, Jeroen (2005): "Efficiency of Large Private Value Auctions," Econometrica, 69(1), 37-68.

Vickrey, William (1961). "Counterspeculation, Auctions, and Competitive Sealed Tenders," The Journal of Finance 16(1), 8-37. 
Individual researchers, as well as the on-line and printed versions of the CERGE-EI Working Papers (including their dissemination) were supported from the following institutional grants:

- Economic Aspects of EU and EMU Entry [Ekonomické aspekty vstupu do Evropské unie a Evropské měnové unie], No. AVOZ70850503, (2005-2010);

- Economic Impact of European Integration on the Czech Republic [Ekonomické dopady evropské integrace na ČR], No. MSM0021620846, (2005-2011);

Specific research support and/or other grants the researchers/publications benefited from are acknowledged at the beginning of the Paper.

(c) Michal Břeský, 2008.

All rights reserved. No part of this publication may be reproduced, stored in a retrieval system or transmitted in any form or by any means, electronic, mechanical or photocopying, recording, or otherwise without the prior permission of the publisher.

Published by

Charles University in Prague, Center for Economic Research and Graduate Education (CERGE) and

Economics Institute ASCR, v. v. i. (EI)

CERGE-El, Politických vězňů 7, 11121 Prague 1, tel.: +420 224005 153, Czech Republic.

Printed by CERGE-EI, Prague

Subscription: CERGE-El homepage: http://www.cerge-ei.cz

Editors: Directors of CERGE and EI

Managing editors: Deputy Directors for Research of CERGE and EI

ISSN 1211-3298

ISBN 978-80-7343-154-9 (Univerzita Karlova. Centrum pro ekonomický výzkum

a doktorské studium)

ISBN 978-80-7344-143-2 (Národohospodářský ústav AV ČR, v. v. i.) 
CERGE-EI

P.O.BOX 882

Politických vězňů 7

11121 Praha 1

Czech Republic http://www.cerge-ei.cz 